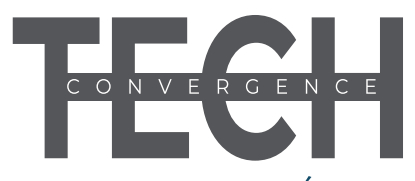

(9)(@)

\title{
ANTES DE LA REFRIGERACIÓN: TÉCNICAS DE CONSERV ACIÓN Y SU APLICACIÓN EN LA GASTRONOMÍA MODERNA
}

\author{
Rodrigo Duarte ${ }^{1}$ \\ Marlene Rojas ${ }^{2}$ \\ Daniel Toledo Ochoa ${ }^{3}$ \\ ${ }^{1}$ Le-Fort. / Le-Fort.org \\ rodrigo@duarte.cl iD https://orcid.org/0000-0002-0884-6911 \\ ${ }^{2}$ Le-Fort. / Le-Fort.org \\ marlene@le-fort.org (D) https://orcid.org/000-0001-6479-619X \\ ${ }^{3}$ Instituto Tecnológico Particular Sudamericano \\ Correro (D) https://orcid.org/0000-0001-5661-662X
}

Fecha de recepción: 15 de noviembre de 2019

Fecha de resultado: 1 de enero de 2020

\section{RESUMEN}

En el presente texto se realiza un repaso de distintas técnicas de conservación comunes antes de que sea posible la refrigeración, tal y como se la conoce hoy en día. Esto con el objetivo de contextualizar dichas prácticas dentro de la evolución gastronómica y como aporte al desarrollo de características organolépticas que, incluso hoy en día, son deseables tanto en la cocina familiar regional como en la denominada alta cocina. Entre estas técnicas destacan: la deshidratación, el curado, el encurtido, la fermentación alcohólica y láctica, entre otras. Para este artículo se aplicaron, por una parte, etapas investigativas basadas en la recopilación bibliográfica sobre procesos conservativos alimentarios y, por otra parte, se desarrollaron y anali-

\section{ABSTRACT}

In the present text, a review of a variation of common techniques to preserve before refrigeration can be carried out, as it is known today. The aim of this research is to contextualize those techniques within the gastronomic evolution, and as a contribution to the development of organoleptic characteristics that, even today, zaron prácticas gastronómicas tomadas, dentro de lo posible, de distintas tradiciones gastronómicas de América del Sur que demuestran el uso de técnicas de conservación como una propuesta culinaria vigente.

Por otro lado, de acuerdo con las tendencias gastronómicas actuales, la pertinencia de esta temática se hace notoria ante una actual tendencia postvanguardista que integra y funde elementos propios de la cocina regional típica con técnicas profesionales gastronómicas. Esto como eje generador de propuestas culinarias donde el sabor y la experiencia vinculada a la alimentación tradicional vuelven a ser prioritarias para restauradores y comensales.

Palabras Clave: conservación, curado, fermentación, secado, salado, liofilización

are desirables both in regional - family cuisine and in the haute cuisine.

Among these stand out: dehydration, seasoning, alcoholic and lactic fermentation, and others. For this article were applied two investigative moments: a bibliography compilation about food conservation processes; and an applicative stage that included the development and analysis of examples that were taken, as far 
as possible, from different gastronomic traditions held in South America that demonstrate the use of conservation techniques as a current culinary proposal. On the other hand, according to the gastronomic trending nowadays, the significance on this matter is highlighted in front of a current post vanguard trend that integrate elements of typical and regional cuisine with pro- fessional gastronomic techniques. All of these as a generator axis of culinary proposals where flavor and the experiences linked to traditional alimentary customs are again at the forefront for restaurateurs and diners.

Keywords: preservation, curing, fermentation, drying, salting, freeze-drying

Forma sugerida de citar: Duarte, R., Rojas, M., \& Toledo Ochoa, D. (2020). Antes de la refrigeración: técnicas de conservación y su aplicación en la gastronomía moderna. Convergence Tech Revista Científica. 4(1), 6-10.

\section{INTRODUCCIÓN}

$\mathbf{P}$ ara sobrevivir, el ser humano ha tenido que recurrir a la naturaleza para conservar sus alimentos: ha aprovechado las condiciones climáticas, utilizando el hielo o los efectos solares con finalidades de preservación (Nummer, 2002). A lo largo del tiempo también ha hecho uso de la acción de microrganismos benéficos. Esto para asegurar los alimentos de la proliferación de microbios perjudiciales a la vez de aportar características organolépticas propias de los procesos que acompañan a este proceso de conservación alimentaria. Todos estos, métodos desarrollados para mantener los alimentos en buen estado y obtener seguridad alimentaria, sobre todo en periodos improductivos.

Así pues, la reciente invención del refrigerador (entre 1867 y 1869) supuso una revolución en los modos de pensar la conservación de los alimentos. Hoy en día, existe una resistencia a conservar alimentos fuera del refrigerador, debido al miedo generalizado a los microorganismos (Katz \& Crisden, 2013, p. 27-30); miedo, por otro lado, que sólo existe desde el descubrimiento de los microbios realizado por Pasteur en 1859 (McGee, 2004, p. 14).

Sin embargo, en años recientes ha habido una serie de propuestas que re-descubren y revalorizan estas técnicas ancestrales, produciendo una creciente variedad de alimentos conservados por deshidratación, curado, fermentación, entre otras técnicas.

Así pues, esta revisión bibliográfica se propone repasar algunas de las técnicas de conservación utilizadas desde tiempos remotos y tiene por objetivo presentar alternativas para que el gastrónomo moderno las desarrolle e incorpore como recursos culinarios.

\section{DESARROLLO}

\section{Técnicas Ancestrales}

Quizá la forma más antigua y extendida a través de la cual el hombre conserva los alimentos sea el secado, que consiste en utilizar el calor para la reducción de la actividad de agua, lo que ralentiza y elimina la proliferación de patógenos (Badui \& Islas, 2013) . De hecho, existe evidencia de secado de alimentos desde hace al menos 12000 años, y es una práctica que ha sido utilizada en todas las regiones en las que esta operación es posible. Así, en aquellas regiones en las que el sol no permite este tipo de conservación, se recurre al ahumado.

En América Latina, el secado de alimentos es una práctica frecuente desde tiempos ancestrales (Park, et. al., 2016, pp. 171-177) y los productos secados siguen presentes en las comidas cotidianas (Mintur, et al., 2013).

El charqui, por ejemplo, es el resultado de una forma ancestral de conservación de la carne mediante el secado (Salvá, et al., 2012, pp. 130). Ya los incas lo preparaban a partir de carne de auquénidos y era un alimento que se servían usualmente los chasquis (mensajeros) que recorrían los caminos del imperio Inca. Con la llegada de los españoles, la variedad de charqui se amplió, incluyendo carne de res y otras especies de carne traídas de Europa. Esta práctica se afianzó de tal modo que se ha convertido en una industria de relevancia, sobre todo en el sur del continente(Argentina y Uruguay), donde existen importantes saladeros.

Otra forma particular de deshidratación es la liofilización; ésta aprovecha la sublimación -el paso directo de fase sólida a fase gaseosa- del hielo para deshidratar el alimento a baja temperatura (Ratti, 2009). El primer caso de liofili- 
zación del que se tiene conocimiento proviene del altiplano de América del Sur, donde se ha logrado deshidratar papas para conservarlas como chuño hasta por 20 años. A continuación, se resume el proceso para producir chuño:

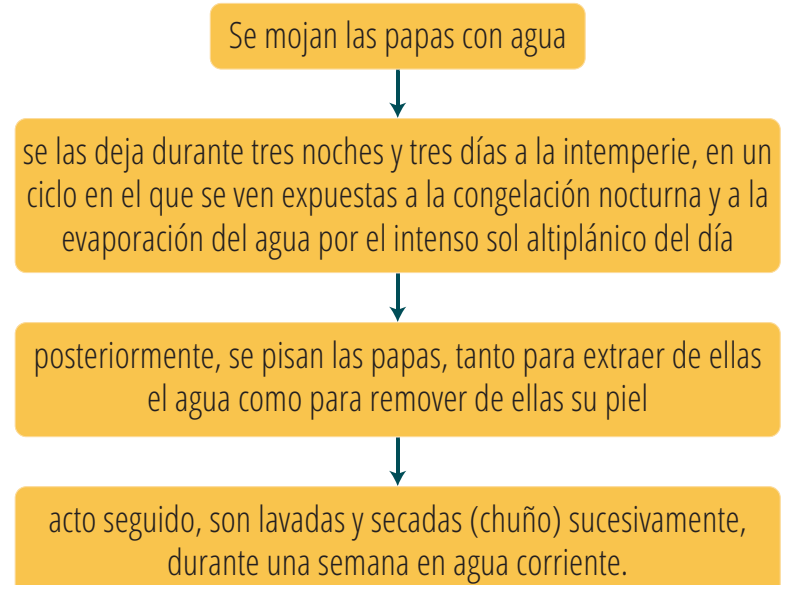

Si bien la técnica proviene de los Andes centrales, se reportan casos de liofilización en el Ecuador, en "las zonas más altas de la sierra, por ejemplo, en los páramos de Cayambe, y en el austro" (Ministerio de Cultura y Patrimonio del Ecuador, s. f.).

Finalmente, vale señalar que, hoy en día, la liofilización es asociada con frecuencia a la producción alimentaria de alta tecnología, posiblemente debido a su utilización en la alimentación de astronautas (NASA, s. f., pp. 82-83).

Una tercera técnica ancestral de deshidratación de los alimentos es el curado, técnica que reduce el agua de los alimentos mediante ósmosis. La conservación en sal, de hecho, es una de las formas más conocidas de conservación de alimentos, con numerosos ejemplos documentados en la antigüedad clásica en Europa, Asia y África. Para no ir muy lejos, Plinio el Viejo, en el libro sexto de su Historia Natural, ya documenta tribus que subsisten únicamente comiendo langostas (el insecto) saladas y ahumadas (Pliny \& Healy, 1991).

Curados frecuentes son los que utilizan no sólo sal, sino además azúcar, especias y sales especiales, como la sal de Praga -que, aparte de proporcionar un color apetitoso a la carne a través del pigmento nitroso-hemoglobina (Hhm, et al., 2017, p. 2), elimina bacterias del género Clostridium-. A partir de tipos de curado parecidos, se preparan el gravlax escandinavo -que consiste en sal- món curado en sal, azúcar y eneldo-, o el bacalao salado, que en Ecuador es usado, principalmente, para la elaboración de fanescas.

Por otro lado, vale señalar que el curado no es una técnica que permite únicamente la conservación de alimentos ricos en proteína, ya que en la cocina de medio Oriente y el norte de África, se ha venido curando en sal el limón desde la Edad Media (Sonneman, 2012).

En todo caso, tal vez sea el jamón, en sus variedades ibérico y prosciutto, la carne curada de mayor prestigio gastronómico en el mundo.

Una cuarta y última forma de conservar los alimentos es la fermentación, a la que se puede definir como "un crecimiento microbiano controlado y conversiones enzimáticas en componentes alimentarios menores y mayores" (Marco et al., 2017, pp. 94 - 102). Existen tres fermentaciones principales:

- La fermentación láctica: presente en células musculares y en bacterias, se da cuando se convierten los azúcares de seis carbonos en ácido láctico (Battcock \& Azam-Ali, 1998), de forma anaeróbica.

- La fermentación alcohólica: se produce cuando los azúcares y otros compuestos se convierten en energía celular, produciendo como deshecho etanol y $\mathrm{CO} 2$.

- La fermentación acética u oxidativa: se genera cuando bacterias aeróbicas convierten el azúcar o el etanol en ácido acético.

\section{Algunos productos fermentados}

Ahora bien, las posibilidades que ofrece la fermentación son muy amplias. Algunos ejemplos son (Katz \& Crisden, 2013): bebidas alcohólicas; vegetales fermentados; bebidas tónicas; fermentados lácteos; granos y tubérculos fermentados; culturas fúngicas; legumbres, semillas y nueces fermentados; carne, pescado y huevos fermentados; aplicaciones no alimentarias.

Carnes: entre las carnes fermentadas se tiene una amplia gama de productos, en su mayoría de origen europeo y asiático; se pueden enumerar así: los salames, los chorizos y otros embutidos (Anagnostopoulos \& Tsaltas, 2019, pp. 257-291). Como curiosidad, quizá valga la pena 
señalar el Hákarl islandés -en cuyo proceso de fermentación, la carne de tiburón se "detoxifica" de su alto contenido de urea por fermentación prolongada- como el ejemplo más exótico de carnes fermentadas.

Vegetales: los vegetales fermentados son muy conocidos y están presentes en distintas culturas. Como ejemplo de ellos, se puede mencionar el kimchi coreano (pepinillos encurtidos) y el sauerkraut alemán (col fermentada). Los vegetales se pueden encurtir por fermentación láctica, que produce ácido láctico o directamente por inmersión en vinagre (ácido acético). El objetivo en ambos casos es mantener un $\mathrm{pH}$ inferior a 4.6 para inhibir el crecimiento de patógenos. Como un dato adicional, se puede mencionar que los encurtidos parecen haber llegado a América con los conquistadores españoles, en la forma de escabeches -derivados estos, a su vez, del al-sikbaj árabe (Freedman, 2009).

Lácteos: los fermentados lácteos son una muy buena forma de conservar un alimento tan perecedero como la leche (McGee, 2004, pp. 44-60); en la cultura occidental abundan los quesos, quesillos, yogures y otros productos lácteos fermentados.

Granos y tubérculos: los granos y tubérculos fermentados no son muy comunes en la gastronomía del Ecuador. Aun así, se pueden mencionar el tocosh -producto andino preparado a partir de la fermentación de papa u otros tubérculos con fines de conservación, al que se le atribuyen propiedades prebióticas (Jiménez et al., 2018, pp. 567-574)o la yuca amarga (Manihot utilissima), fermentada con la finalidad de neutralizar sus glicósidos cianogénicos antes de cocinar (Obi et al., 2019, pp. 1-10).

Entre esta amplia variedad de posibilidades, quizá la fermentación más cercana a la cultura andina sea la fermentación alcohólica, en forma de chicha. Como es sabido, la chicha es una bebida que se puede preparar a través de la fermentación de distintos sustratos. En Ecuador, la variedad más familiar es la chicha de maíz -aunque existan otras, como la chicha de yuca, de ungurahua y de guarango-. Esta bebida puede fermentarse a través de azúcares, ya sea producidos por malteado -como se da al producir chicha de jora-, ya sea producidos por añadido, enzimáticamente -como sucede en la preparación de la chicha masticada- (Ministerio de Cultura y Patrimonio del Ecuador, 2016).

\section{CONCLUSIONES Y RECOMENDACIONES}

A partir de lo revisado se puede concluir, ante todo, que hay una gran variedad de técnicas de conservación de alimentos que han sido cultivadas a lo largo de miles de años y que, con procesos propios de modernización más concretamente: con la implementación de la refrigeración como medio de conservación de los alimentos-, han pasado a segundo plano.

Ahora bien, si, por otro lado, se considera que la postvanguardia gastronómica se "caracteriza por la asimilación de todo lo que ha pasado y por la afirmación de vías culinarias totalmente diversas" (Pérez-Lozano, 2013), se comprende que el actual es un buen momento para recuperar los aportes que brindados por las técnicas de conservación aquí expuestas. Aprovechar tales contribuciones, de hecho, permitirían, no sólo cierto rescate de sabores tradicionales (Lum \& Ferrière Le Vayer, 2016), sino también cierta renovación de las tradiciones (Volkening, 2008, p. 186-195).

Existe, en este sentido, un renovado interés en el uso de microorganismos en relación al desarrollo de alimentos, diseño de sabores e innovación culinaria (Johnson, 2016; Mouritsen \& Styrbæk, 2017) que toma las técnicas tradicionales previas a la refrigeración y las utiliza como una herramienta de innovación. Aquí es donde se genera la posibilidad de tomar los agrios, las chichas, los ceviches para darles nueva vida, integrando prácticas propias y exóticas, conociendo y respetando cada una de las tradiciones utilizadas.

\section{BIBLIOGRAFÍA}

Anagnostopoulos, D. A., \& Tsaltas, D. (enero, 2019). Fermented Foods and Beverages. Innovations in Traditional Foods, 257-291. Recuperado de https:// doi.org/10.1016/B978-0-12-814887-7.00010-1

Badui Dergal, S., y Pedroza Islas, R. (2013). Química de los alimentos. Naucalpan de Juárez (México): Pearson Educación.

Battcock, M., \& Azam-Ali, S. (1998). Fermented fruits and vegetables: A global perspective. Roma: Food and Agriculture Organization of the United Nations.

Freedman, P. (2009). Gastronomía: Historia del paladar. 
Valencia: Publicacions de la Universitat de València.

Hhm, H., Ma, M., Jin, G., \& He, L. (2017). NitrosoHemoglobin Preparation and Meat Product Colorant Development. Journal of Food Processing \& Technology, 08(02). doi: 10.4172/21577110.1000658

Jiménez, E., Yépez, A., Pérez-Cataluña, A., Ramos Vásquez, E., Zúñiga Dávila, D., Vignolo, G., \& Aznar, R. (enero, 2018). Exploring diversity and biotechnological potential of lactic acid bacteria from tocosh-Traditional Peruvian fermented potatoes-By high throughput sequencing (HTS) and culturing. LWT, 87, 567-574. Recuperado de https:// doi.org/10.1016/j.lwt.2017.09.033

Johnson, A. J. (marzo, 2016). Artisanal food microbiology. Nature Microbiology, 1(4). Recuperado de https://doi.org/10.1038/nmicrobiol.2016.39

Katz, S. E., \& Crisden, S. (2013). The art of fermentation: An in-depth exploration of essential concepts and processes from around the world. Vermont: Chelsea Green.

Lum, C. M. K., \& Ferrière Le Vayer, M. (Eds.). (2016). Urban foodways and communication: Ethnographic studies in intangible cultural food heritages around the world. Lanham: Rowman \& Littlefield.

Marco, M. L., Heeney, D., Binda, S., Cifelli, C. J., Cotter, P. D., Foligné, B., ... Hutkins, R. (abril, 2017). Health benefits of fermented foods: Microbiota and beyond. Current Opinion in Biotechnology, 44, 94-102. Recuperado de https://doi.org/10.1016/j. copbio.2016.11.010

McGee, H. (2004). On Food and Cooking: The Science and Lore of the Kitchen. New York: Scribner.

Ministerio de Cultura y Patrimonio del Ecuador. (2016). Chicha. Patrimonio Alimentario website Recuperado de: http://patrimonioalimentario.culturaypatrimonio.gob.ec/wiki/index.php/ Chicha\#Ingredientes_tradicionales

Ministerio de Cultura y patrimonio del Ecuador. (n.d.). Papa chuno. Patrimonio Alimentario website. Recuperado de: http://patrimonioalimentario.culturaypatrimonio.gob.ec/wiki/index.php/Papa_chuno

Mintur, Ministerio Coordinador de Patrimonio, \& Asociación de Chefs del Ecuador. (2013). Ecuador culinario: Saberes y sabores. Quito: MINTUR.
Mouritsen, O., \& Styrbæk, K. (2017). Mouthfeel: How Texture Makes Taste(Arts and Traditions of the Table: Perspectives on Culinary History) (M. Johansen, Trad.). New York: Columbia University Press.

National Aeronautics and Space Administration (NASA). (n.d.). Space Food. 82-83. Recuperado de https://www.nasa.gov/pdf/146852main_Food_ for_Spaceflight_Educator.pdf

Nummer, B. (mayo, 2002). Historical Origins of Food Preservation. National Center for Home food Preservetion. Recuperado de https://nchfp.uga.edu/ publications/nchfp/factsheets/food_pres_hist.html

Obi, C. N., Okezie, O., \& Ukaegbu, T. (julio, 2019). Fermentation Reduces Cyanide Content during the Production of Cassava Flours from Sweet and Bitter Cassava Tuber Varieties. Asian Food Science Journal, 1-10. Recuperado de https://doi. org/10.9734/afsj/2019/v11i130050

Park, S., Hongu, N., \& Daily, J. W. (septiembre, 2016). Native American foods: History, culture, and influence on modern diets. Journal of Ethnic Foods, 3(3), 171-177. Recuperado de https://doi.org/10.1016/j.jef.2016.08.001

Pérez-Lozano, J. (3 de julio de 2013). Entrevista a Philippe Regol, Premio Nacional de Gastronomía. Gastroactitud. Recuperado 30 de octubre de 2019, de Gastroactitud website: https://www.gastroactitud.com/pista/entrevista-a-philippe-regol-premio-nacional-de-gastronomia/

Pliny, \& Healy, J. F. (1991). Natural history, a selection. New York: Penguin Books.

Ratti, C. (noviembre, 2008). Advances in food dehydration. Recuperado de http://www.crcnetbase.com/ isbn/9781420052534

Salvá, B. K., Fernández-Diez, A., Ramos, D. D., Caro, I., \& Mateo, J. (enero, 2012). Chemical composition of alpaca (Vicugna pacos) charqui. Food Chemistry, 130(2), 329-334. Recuperado de https://doi.org/10.1016/j.foodchem.2011.07.046

Sonneman, T. F. (2012). Lemon: A global history. London: Reaktion Books.

Volkening, T. (octubre, 2008). Renewing America's Food Traditions (RAFT). Journal of Agricultural \& Food Information, 9(3), 186-195. Recuperado de https:// doi.org/10.1080/10496500802286087 